\title{
Psychological Impact, Self-perception and the Contributing Factors in Patients with Androgenetic Alopecia
}

\author{
$\mathrm{Ng} \mathrm{KF}^{1^{*}}$, Norazirah $\mathrm{MN}^{2}$, Mazlin $\mathrm{MB}^{3}$, Adawiyah $\mathrm{J}^{2}$, and Shamsul $\mathrm{AS}^{4}$ \\ ${ }^{1}$ Department of Medicine, the National University of Malaysia Medical Centre, Kuala Lumpur, Malaysia
}

${ }^{2}$ Department of Dermatology, the National University of Malaysia Medical Centre, Kuala Lumpur, Malaysia

${ }^{3}$ Department of Dermatology, KPJ Ampang Puteri Specialist Hospital, Malaysia

${ }^{4}$ Department of Community Health, the National University of Malaysia Medical Centre, Kuala Lumpur, Malaysia

"Corresponding author: Kim Fong Ng, Department of Medicine, the National University of Malaysia Medical Centre, Jalan Yaacob Latif, 56000 Cheras, Kuala Lumpur, Malaysia, Tel: +60163339283; E-mail: ngkimfong81@gmail.com

Received date: August 01, 2017; Accepted date: August 22, 2017; Published date: August 26, 2017

Copyright: $\odot 2017 \mathrm{Ng} \mathrm{KF}$, et al. This is an open-access article distributed under the terms of the Creative Commons Attribution License, which permits unrestricted use, distribution, and reproduction in any medium, provided the original author and source are credited.

\begin{abstract}
Background: Androgenetic alopecia (AGA) is a common hair disorder which affects the patients' psychology and social activities. Despite being the most prevalent alopecia in Malaysia, there are limited studies examining its psychological impact and patient's perception on AGA. This study assessed these effects and determined their contributing factors in AGA patients.

Methods: A prospective observational study was conducted involving all AGA patients attending dermatology clinics at two tertiary centers. Psychological impact was assessed using Hospital Anxiety and Depression Scale (HADS). Patient's perception was assessed using Visual Analog Scale (VAS).

Results: Sixty male patients and 41 female patients were recruited. The median age of patients was 29 years. The ethnic composition was Malay $(30.7 \%)$, Chinese $(34.7 \%)$ and Indian (34.6\%). More females experienced mild AGA-related anxiety and depression compared to males $(\mathrm{P}<0.001)$. Young (age $<40$ years) and single individuals experienced more anxiety and depression than older, married patients $(P<0.001)$. Patients who adopted coping strategies reported more anxiety $(P=0.002)$ and depression $(P<0.001)$ compared to those who were not using any coping strategy. Women were more dissatisfied with their hair condition (VAS score=4 [3])) compared to men (VAS score=5 [3]; $P=0.002$ ).

Conclusion: AGA impairs patients' psychology and affects their self-perception. Age less than 40 years old, female, unmarried, disease duration less than 4 years and adopting coping strategies were significant factors influencing the psychological impact and perception in AGA patients. Hence, early integration of psychological support to treatment of AGA is recommended.
\end{abstract}

Keywords: Androgenetic alopecia; Anxiety; Hair transplantation

\section{Introduction}

Androgenetic alopecia (AGA) is a common hair disorder [1] which usually begins between the ages of 12 to 40 years old [2]. In Asian countries, the prevalence of AGA is higher in males than females. In Korea, the reported prevalence is $14.1 \%$ in men and $5.6 \%$ in women [3]. In China, it was $21.3 \%$ in men and $6 \%$ in women [4]. A much higher prevalence of $63 \%$ was reported in Singaporean men [5]. In Malaysia, AGA is the most prevalent type of alopecia reported [6,7]. The most common ethnics affected by this condition here were Malays (42.1\%), followed by Indians (26.3\%), Chinese $(26.3 \%)$ and others (5.3\%) [1].

Hair plays an important role in determining self-image, identity, social perception and psychosocial functioning [8]. \{J. Passchier Ph.D., July $1988 \# 59$ \} Due to this reason, even a clinically imperceptible hair loss had been reported to be associated with reduced quality of life (QoL) [9]. Studies had highlighted several AGA-related negative psychological impacts such as anxiety, depression, low self-esteem and feeling unattractive $[10,11]$. These negative feelings may also lead to marital or sexual problems [12].

AGA not only causes psychological disturbances due to the nature of the disease, but also by its limited pharmacological therapies to prevent further progression of hair loss or in a minority to stimulate partial regrowth [13]. Some patients are managing their condition with camouflage techniques $[14,15]$ and studies have shown that poor coping strategies for AGA may contribute to more negative perception of hair loss and self-image [16], thus adding onto the overall damaging psychological impact. Consequently, understanding the psychosocial aspect and perception of patients with AGA has become a matter of great concern. In Malaysia particularly, there is paucity in research exploring the patient's belief on AGA and how it relates to their mental health. Hence, the aims of this study were to investigate the psychological impact of AGA to the patients and their perception of their hair condition. Factors which could influence these effects were also investigated. 
Citation: $\quad \mathrm{Ng} \mathrm{KF}$, Norazirah MN, Mazlin MB, Adawiyah J, Shamsul AS (2017) Psychological Impact, Self-perception and the Contributing Factors in Patients with Androgenetic Alopecia. J Cosmo Trichol 3: 123. doi:10.4172/2471-9323.1000123

Page 2 of 7

\section{Materials and Methods}

\section{Patients and study design}

We conducted a cross-sectional, observational study at the Dermatology Outpatient Clinics in The National University of Malaysia Medical Centre and Kuala Lumpur General Hospital over 1 year starting June 2015. The study was approved by The National University of Malaysia Research Ethic Committee (UKM 1.5.3.5/244/ FF-2014-358) and the Medical Research Ethics Committee, Ministry of Health (NMRR-16-358-29565). All participants provided their written informed consent. We included patients aged 16 years and above with clinical diagnosis of AGA of all severities, who could understand and complete the questionnaires in English or Malay version. We excluded patients who were on medications that could cause alopecia, those with other types of alopecia and those with medical conditions which could lead to alopecia. Patients were asked to answer the Hospital Anxiety and Depression Scale (HADS) questionnaire and to rate subjectively the severity of their hair condition using the Visual Analog Scale (VAS).

\section{Assessment}

Hospital anxiety and depression scale (HADS): This is a validated questionnaire consisted of 14 items specifically designed for screening anxiety and depressive symptoms. It has two subscales: seven items reflecting anxiety (HADS-A) and seven items reflecting depression (HADS-D). The anxiety and depression subscales are scored from 0 to 3 (four-point Likert scales), giving maximum scores of 21 for anxiety and depression respectively. Score 7 or below is considered "normal/no problem". Scores 8-10 indicates "mild"; 11-14 indicates "moderate" and 15-21 indicates "severe". A score of 11 or higher indicates probable presence of the mood disorder namely anxiety or depression [17].

Visual analogue scale (VAS): A score ranging from 0 (completely dissatisfied) to 10 (completely satisfied) was used to gauge the patient's perception on the severity of their hair condition. A validated Malay version of the questionnaire was utilized $[16,17]$.

\section{Statistical analyses}

Data were analyzed using Statistical Package for the Social Sciences (SPSS) software (version 22 for Windows; IBM-SPSS, Chicago, IL, USA). The qualitative data were presented in the forms of frequencies and percentages. Median (interquartile range $[\mathrm{IQR}]$ ) were used for quantitative data. Kruskal Wallis test was used to compare HADS-A, HADS-D and VAS scores in different age groups, ethnicities, education levels, income and disease severity. Mann-Whitney $U$ test was used to compare HADS-A, HADS-D, and VAS in gender, marital status and disease duration. Spearman rank correlation test (non-parametric) was used to establish the correlation between VAS and HADS scores. P values were considered significant when less than 0.05 .

\section{Results}

\section{Demographic characteristics}

A total of 101 patients were recruited; $59.4 \%$ were males and $40.6 \%$ females. The median (IQR) age was 29 (16) years. The ethnic compositions of these patients were Malay (30.7\%), Chinese (34.7\%), and Indian (34.6\%). More than half of patients were single and received tertiary education and $30.7 \%$ were professionals. There were
$36.6 \%$ of female patients had mild disease, $48.8 \%$ had moderate disease and $14.6 \%$ patients had severe disease. Among male patients, $18.3 \%$ had mild AGA, $36.7 \%$ had moderate disease and $45 \%$ with severe AGA. The median (IQR) duration of disease was 3 years. There were $57.4 \%$ patients had family history of AGA. The demographic characteristics of the patients were presented in Table 1.

\begin{tabular}{|c|c|}
\hline Variables & Number (\%) \\
\hline \multicolumn{2}{|l|}{ Age } \\
\hline$<20$ & $8(7.9)$ \\
\hline $20-39$ & $56(55.5)$ \\
\hline $40-59$ & $27(26.7)$ \\
\hline$>60$ & $10(9.9)$ \\
\hline \multicolumn{2}{|l|}{ Ethnicity } \\
\hline Malay & $31(30.7)$ \\
\hline Chinese & $35(34.7)$ \\
\hline Indian & $35(34.6)$ \\
\hline \multicolumn{2}{|l|}{ Disease Duration } \\
\hline$<4$ years & $55(54.5)$ \\
\hline$>4$ years & $46(45.5)$ \\
\hline \multicolumn{2}{|l|}{ Education level } \\
\hline Primary & $5(5)$ \\
\hline Secondary & $33(32.6)$ \\
\hline Tertiary & $63(62.4)$ \\
\hline \multicolumn{2}{|l|}{ Marital Status } \\
\hline Single & $53(52.5)$ \\
\hline Married & $47(46.5)$ \\
\hline Widowed & $1(1)$ \\
\hline \multicolumn{2}{|l|}{ Income per month } \\
\hline RM0 & $18(17.8)$ \\
\hline$<$ RM1000 & $4(4)$ \\
\hline RM1000-3000 & $33(32.7)$ \\
\hline$>$ RM3000 & $46(45.5)$ \\
\hline \multicolumn{2}{|l|}{ Occupation } \\
\hline Manager & $8(7.9)$ \\
\hline Professional & $31(30.7)$ \\
\hline Technical & $10(9.9)$ \\
\hline Administrative & $17(16.8)$ \\
\hline Sales and Customer service & $10(9.9)$ \\
\hline Unemployed, pensioner & $11(10.9)$ \\
\hline Student & $14(13.9)$ \\
\hline
\end{tabular}


Citation: $\quad \mathrm{Ng} \mathrm{KF}$, Norazirah MN, Mazlin MB, Adawiyah J, Shamsul AS (2017) Psychological Impact, Self-perception and the Contributing Factors in Patients with Androgenetic Alopecia. J Cosmo Trichol 3: 123. doi:10.4172/2471-9323.1000123

Page 3 of 7

\begin{tabular}{|l|l|}
\hline Disease Severity & \\
\hline Ludwig scale & \\
\hline Mild & $15(36.6)$ \\
\hline Moderate & $20(48.8)$ \\
\hline Severe & $6(14.6)$ \\
\hline Variables & Number (\%) \\
\hline Disease Severity & \\
\hline Norwood-Hamilton scale & \\
\hline Mild & $11(18.3)$ \\
\hline Moderate & $22(36.7)$ \\
\hline Severe & $27(45)$ \\
\hline Coping Strategies & \\
\hline Male & \\
\hline With coping strategies & $24(40)$ \\
\hline Without coping strategies & $36(60)$ \\
\hline Female & \\
\hline With coping strategies & $31(75.6)$ \\
\hline Without coping strategies & $25(45.5)$ \\
\hline No coping strategies & $3(3)$ \\
\hline Non-invasive coping strategies & \\
\hline Invasive coping strategies (hair transplant) & \\
\hline Mode of coping strategies used & \\
\hline Change hairstyle & \\
\hline
\end{tabular}

\begin{tabular}{|l|l|}
\hline Wear head scarf & $17(30.9)$ \\
\hline Wear wigs & $6(10.9)$ \\
\hline Wear cap & $4(7.3)$ \\
\hline Hair transplantation & $3(5.4)$ \\
\hline
\end{tabular}

Table 1: Patient demographic characteristics.

Most patients adopted coping strategies; majority being females. There were $45.5 \%$ patients changed their hairstyles, $30.9 \%$ wore head scarves, $10.9 \%$ wore wigs, $7.3 \%$ patients wore caps to conceal localized patches of alopecia and $5.5 \%$ patients had hair transplantation (Table 1).

The median (IQR) HADS-A score for total sample size was 7(5). This reflects no anxiety amongst AGA patients. Nevertheless, when comparing the median HADS-A according to gender, females had a significantly higher score (median [IQR] 8 (6) than males (median (IQR) 5 (5.75)) $(\mathrm{P}<0.001)$. The overall median (IQR) HADS-D score was 6 (7) but again, females experienced depression significantly with HADS-D score (median (IQR) 8 (8.5)) compared to males with AGA (median (IQR) 5 (7)). The median HADS scores were significantly higher in patients who had AGA for less than 4 years compared to those where the disease was presented for 4 years and above. There was no significant difference in HADS-A and HADS-D among male patients throughout the disease severity spectrum. However, anxiety and depressive symptoms were reported in females from all disease severity. Patients who use coping strategies for AGA reported more anxiety $(\mathrm{P}=0.002)$ and depression $(\mathrm{P}<0.001)$ with their hair condition compared to those who did not adopt any coping strategy. There were no significant differences in median HADS-A and HADS-D scores among different education levels, occupations, ethnicities and monthly income. Individuals less than 40 years $(\mathrm{P}<0.001)$ and single $(\mathrm{P}<0.001)$ had significantly more anxiety and depression than older, married patients (Table 2 and Table 3 ).

\begin{tabular}{|c|c|c|c|c|c|c|}
\hline Variables & $\begin{array}{l}\text { HADS-A } \\
\text { Median } \\
\text { (p25-p75) }\end{array}$ & $\begin{array}{l}\text { Comparison of patient } \\
\text { groups for HADS-A } \\
\text { scores }\end{array}$ & $\begin{array}{l}\text { P value } \\
\text { (b) }\end{array}$ & $\begin{array}{l}\text { HADS-D } \\
\text { Median } \\
\text { (p25-p75) }\end{array}$ & $\begin{array}{l}\text { Comparison of patient } \\
\text { groups } \\
\text { For HADS-D scores }\end{array}$ & $P$ value (b) \\
\hline \multicolumn{7}{|l|}{ Age } \\
\hline 1. $<20$ & $8(5.75-14)$ & 1 vs. 2 & 0.759 & $8(6.5-17)$ & 1 vs. 2 & 0.386 \\
\hline 2. $20-39$ & $8(6-10)$ & 1 vs. 3 & 0.007 & $7.5(5-10.75)$ & 1 vs. 3 & 0.011 \\
\hline 3. $40-59$ & $5(2-6)$ & 1 vs. 4 & 0.005 & $2(1-5)$ & 1 vs. 4 & 0.017 \\
\hline \multirow[t]{3}{*}{ 4. $>60$} & $1(0-6)$ & 2 vs. 3 & $<0.001$ & $1.5(0-6)$ & 2 vs. 3 & $<0.001$ \\
\hline & & 2 vs. 4 & $<0.001$ & & 2 vs. 4 & 0.001 \\
\hline & & 3 vs. 4 & 0.115 & & 3 vs. 4 & 0.488 \\
\hline \multicolumn{7}{|c|}{ Disease Severity } \\
\hline \multicolumn{7}{|c|}{ Ludwig scale } \\
\hline Mild & $7(5-8)$ & Mild-moderate & 0.068 & $4(3-6)$ & Mild-moderate & 0.001 \\
\hline Moderate & $9(6-19.75)$ & Mild-severe & 0.002 & $9(6.25-12)$ & Mild-severe & 0.001 \\
\hline
\end{tabular}


Citation: $\quad \mathrm{Ng} \mathrm{KF}$, Norazirah MN, Mazlin MB, Adawiyah J, Shamsul AS (2017) Psychological Impact, Self-perception and the Contributing Factors in Patients with Androgenetic Alopecia. J Cosmo Trichol 3: 123. doi:10.4172/2471-9323.1000123

Page 4 of 7

\begin{tabular}{|l|l|l|l|l|l|l|}
\hline Severe & $15.5(9.5-17.5)$ & Moderate-severe & .021 & $18(13.5-19)$ & Moderate-severe & 0.006 \\
\hline P value (a) & 0.018 & & & 0.001 & \\
\hline $\begin{array}{l}\text { Norwood-Hamilton } \\
\text { scale }\end{array}$ & & & & & \\
\hline Mild & $4(2-8)$ & & & $3(1-8)$ & \\
\hline Moderate & $5(3.5-8.25)$ & & & $5.5(1.75-7.25)$ & & \\
\hline Severe & $5(2-9)$ & & & $3(1-9)$ & & \\
\hline P value (a) & 0.802 & & & 0.455 & & \\
\hline
\end{tabular}

Table 2: HADS-A and HADS-D scores according to age and disease severity (Abbreviations: HADS-A, Hospital anxiety and depression scaleanxiety subscale; HADS-D, Hospital anxiety and depression scale-depression subscale; vs: versus; (1): <20; (2): 20-39; (3): 40-59; (4):>60 (a) overall $\mathrm{P}$ value calculated using Kruskal Wallis test, (b) data compared using Mann-Whitney U test.

The median (IQR) VAS score for total sample size was 4 (3). Females had lower VAS score (4 [3]) than males (5 [3]) (P=0.002). The median VAS score was significantly lower in patients with AGA for less than 4 years compared to those with disease duration of 4 years or more $(\mathrm{P}<0.001)$. With regards to disease severity, there was no significant difference in patients' perception regarding their hair loss for both males $(\mathrm{P}=0.057)$ and females $(\mathrm{P}=0.555)$. Consistently, patients who used invasive or non-invasive coping strategy for AGA were found to be more dissatisfied with their hair condition compared to those who did not adopt any coping strategy $(\mathrm{P}=0.021)$. There was significant difference in median VAS score among different education levels whereby patients who only received primary education had higher
VAS score (7 (3.5)) compared to those with secondary (5 (2.5)) and tertiary education levels (4 (3)) $(\mathrm{P}=0.004)$. Significant differences in median (IQR) VAS scores were also observed across various occupations where managers $(7(7))$, pensioners and unemployed individuals (7 (3)) had the highest VAS scores, followed by technical (5 (4)), professionals (4 (3)), administrative (4 (3)), sales and customer service (4 (4.5)) and students $(3.5(1.5))$. $\mathrm{P}=0.009$, No significant difference in VAS score was reported across different ethnicities, $\mathrm{P}=0.089$, and monthly income $\mathrm{P}=0.061$. Previous studies observed, age less than 40 years $(\mathrm{P}<0.001)$ and single $(\mathrm{P}<0.001)$. AGA patients were more dissatisfied with their hair condition compared to older, married patients (Table 3 and Table 4).

\begin{tabular}{|c|c|c|c|}
\hline Variables & $\begin{array}{l}\text { HADS-A } \\
\text { Median } \\
(\mathrm{p} 25-\mathrm{p} 75)^{\mathrm{a}}\end{array}$ & $\begin{array}{l}\text { HADS-D } \\
\text { Median } \\
(\mathrm{p} 25-\mathrm{p} 75)^{\mathrm{a}}\end{array}$ & $\begin{array}{l}\text { VAS } \\
\text { Median } \\
(\mathrm{p} 25-\mathrm{p} 75)^{\mathrm{a}}\end{array}$ \\
\hline \multicolumn{4}{|c|}{ Disease Duration } \\
\hline$<4$ years & $8(5-10)$ & $8(5-12)$ & $4(2-5)$ \\
\hline$\geq 4$ years & $5(2-8)$ & $3(1-7.25)$ & $6(4-7.25)$ \\
\hline$P$ value & $<0.001$ & $<0.001$ & $<0.001$ \\
\hline \multicolumn{4}{|l|}{ Ethnicity } \\
\hline Malay & $7(5-9)$ & $6(3-8)$ & $5(4-7)$ \\
\hline Chinese & $8(4-10)$ & $6(3-10)$ & $4(3-5)$ \\
\hline Indian & $6(2.75-10)$ & $6.5(1-11.25)$ & $5(3-7)$ \\
\hline$P$ value & 0.755 & 0.610 & 0.089 \\
\hline \multicolumn{4}{|c|}{ Education level } \\
\hline Primary & $0(0-5)$ & $1(0-4.5)$ & $7(5-8.5)$ \\
\hline Secondary & $7(4-9)$ & $5(2-8)$ & $5(3.5-6)$ \\
\hline Tertiary & $8(5-10)$ & $7(3-10)$ & $4(3-6)$ \\
\hline$P$ value & 0.05 & 0.082 & 0.004 \\
\hline Marital statu & & & \\
\hline
\end{tabular}


Citation: $\quad \mathrm{Ng} \mathrm{KF}$, Norazirah MN, Mazlin MB, Adawiyah J, Shamsul AS (2017) Psychological Impact, Self-perception and the Contributing Factors in Patients with Androgenetic Alopecia. J Cosmo Trichol 3: 123. doi:10.4172/2471-9323.1000123

Page 5 of 7

\begin{tabular}{|c|c|c|c|}
\hline Single & $8(6.5-10)$ & $8(5-11.5)$ & $3(2-4)$ \\
\hline Married & $5(2-7)$ & $3(1-6)$ & $6(5-8)$ \\
\hline$P$ value & $<0.001$ & $<0.001$ & $<0.001$ \\
\hline \multicolumn{4}{|l|}{ Income per month } \\
\hline RMO & $8(4-11.5)$ & $6.5(4-10.5)$ & $4(2.75-5)$ \\
\hline$<$ RM1000 & $5.5(5-8.25)$ & $4.5(2.25-8.25)$ & $6.5(5.25-7)$ \\
\hline RM1000-3000 & $6(3-9)$ & $6(2-8.5)$ & $4(2.5-6)$ \\
\hline$>\mathrm{RM} 3000$ & $7(4-9.25)$ & $5(2-10)$ & $4.5(3-7)$ \\
\hline$P$ value & 0.227 & 0.843 & 0.061 \\
\hline \multicolumn{4}{|l|}{ Occupation } \\
\hline Manager & $4(2-7.75)$ & $2(1-6.5)$ & $7(4.5-8.75)$ \\
\hline Professional & $8(5-10)$ & $6(3-9)$ & $4(3-6)$ \\
\hline Technical & $5(2.25-8.25)$ & $4(2.75-9)$ & $5(2.75-6.75)$ \\
\hline Administrative & $6(3.5-8)$ & $8(2-9.5)$ & $4(3-6)$ \\
\hline Sales and Customer service & $9(6.5-10)$ & $9(3.75-12)$ & $4(1.5-6)$ \\
\hline Unemployed, pensioner & $5(0-8)$ & $2(0-6)$ & $7(5-8)$ \\
\hline Student & $8(6.25-12)$ & $7(4.75-11.5)$ & $3.5(2.75-4.25)$ \\
\hline$P$ value & 0.178 & 0.123 & 0.009 \\
\hline \multicolumn{4}{|l|}{ Coping strategies } \\
\hline None & $5(2-8)$ & $3(1-6.25)$ & $5.5(4-8)$ \\
\hline Non-invasive & $8(6-10)$ & $8(5-11)$ & $4(3-5)$ \\
\hline Invasive (hair transplantation) & $10(2-19)$ & $19(1-19)$ & $0(0-2)$ \\
\hline$P$ value & 0.002 & $<0.001$ & 0.021 \\
\hline
\end{tabular}

Table 3: Correlation between single variable to HADS-A, HADS-D and VAS (Abbreviations: HAD-A: Hospital Anxiety and Depression ScaleAnxiety subscale; HADS-D: Hospital Anxiety and Depression Scale-Depression subscale; VAS: Visual Analog Scale (a) Data presented are the median and 25th-75th percentile.

\begin{tabular}{|l|l|l|l|l|}
\hline Variables & $\begin{array}{l}\text { VAS } \\
\text { Median } \\
(\mathbf{p 2 5 - p 7 5 )}\end{array}$ & P value $^{(a)}$ & $\begin{array}{l}\text { Comparison } \\
\text { of patient } \\
\text { groups }\end{array}$ & P value $^{(b)}$ \\
\hline Age & & & & \\
\hline $1 .<20$ & $3(1.25-4)$ & & 1 vs. 2 & 0.227 \\
\hline $2.20-39$ & $4(2.25-5)$ & $<0.001$ & 1 vs. 3 & $<0.001$ \\
\hline $3.40-59$ & $6(5-7)$ & & 1 vs. 4 & 0.001 \\
\hline $4 .>60$ & 7.5 & & 2 vs. 3 & $<0.001$ \\
\hline & $(5.75-9.25)$ & & 2 vs. 4 & $<0.001$ \\
\hline & & & 3 vs. 4 & 0.071 \\
\hline
\end{tabular}

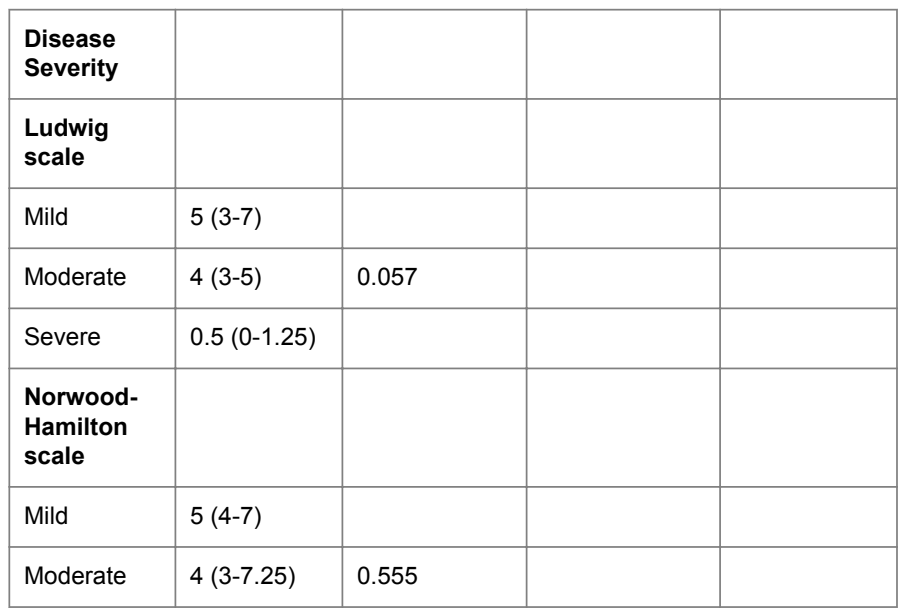


Severe $6(4-7)$

Table 4: VAS scores according to age and disease severity (Abbreviation: VAS: Visual Analog Scale; (1): <20; (2): 20-39; (3): 40-59; (4): >60 (a) overall P value calculated using Kruskal Wallis test, (b) data compared using Mann-Whitney U test).

\section{Correlation of HADS and VAS scores}

Significant negative correlation was also observed between HADS-A and VAS scores $(\mathrm{r}=-0.692 ; \mathrm{P}<0.001)$ and between HADS-D and VAS scores $(\mathrm{r}=0.733 ; \mathrm{P}<0.001)$.

\section{Discussion}

The association between AGA and psychological disorders is well documented [18]. Our study shows that AGA had negative psychological impact especially in female patients who experienced mild anxiety and depression. This finding is comparable to studies by Aldermir et al. [19], Yu et al. [20] and Tabolli et al. [21]. On average, AGA patients were not satisfied with their hair condition as reflected by their VAS. We also found a negative correlation between HADS and VAS which is consistent with the study by Schmidt et al. [9] and Yu et al. [20]. The reason for this may be due to the influence of negative emotions onto self-perception.

Patients aged less than 40 years old experienced worse anxiety and depression compared to older patients. This is in agreement with five other studies [10,20,22-24] which also reported greater degree of psychological impact among younger patients. Early onset of hair loss negatively affects self-image and self-esteem in these patients. Low selfesteem makes it more difficult when looking for life partners and employment [25]. Moreover, peer pressure exaggerates the need for social acceptance which could lead to feelings of stigmatization. These subsequently cause younger patients to be more vulnerable to depression and anxiety [26]. On the contrary, older patients were least affected psychologically. This might be explained by the fact that older patients are more established in their occupation and marital life therefore, external appearance has very small psychological impact on their lives. Our finding is in direct contrast to Sawant et al. [27], who noticed younger patients had less depression and anxiety compared to older patients. On the other hand, there were also studies, which found no significant differences in perception of hair condition [28] and psychological aspect [29] across different age groups.

Our study also found that younger patients had negative perception of their hair condition while other study did not find any difference [28]. One possible explanation for our observation is that when patients are psychologically disturbed by their hair condition; this results in an undesirable perception.

Single individuals were found to experience more anxiety and depression and were more dissatisfied with their hair condition compared to those who were married. This finding concurs with other studies [30,31] and may be explained by the fact that physical attractiveness is known to affect dating [32]. Both men and women believe that hair loss will erode their chances in romance [33] because baldness is often perceived as an unattractive quality. This is also supported by the findings from Lee et al. [32], where over $90 \%$ of women and non-balding men responded that balding men had a disadvantage in dating or marriage.
Similar to the trend seen in other studies $[10,28]$, our study shows female patients with more severe AGA felt more depressed and anxious compared to the males. This is because women regard hair as an indicator of personality, femininity, attractiveness and sexuality $[10,23]$. This result was not observed in male patients presented with varying degrees of AGA severity. Our finding is in contrast to Yu et al. [20] and Kranz et al. [29] who found young men with more severe AGA reported higher level of psychological distress, anxiety, and depression.

In patients with alopecia for less than 4 years, AGA caused the patients to be more depressed, anxious and dissatisfied with their hair condition compared to those with longer disease duration. These findings suggest that patients experience non-acceptance, depression and anxiety at the beginning of the disease but these feelings become attenuated over time as patients adapt to the condition by developing the necessary positive coping skills. This also highlights that it takes a long time for patients to accept the nature of this condition which is almost similar to coping with chronic medical conditions [18]. Our findings are in contrast with studies by Cash et al. [31] and Han et al. [22] who reported psychological aspect was more severely afflicted in patients who had a longer duration of AGA. However, there were also studies showing no significant association between disease duration and psychological impact $[20,23,28]$.

Although there was no significant difference in HADS scores in different education levels, occupations and monthly income, we observed that those who received secondary and tertiary education were remarkably more dissatisfied with their hair condition. This could be due to their increased awareness and self-consciousness about image and the need for high degree of social interaction in these group of patients [30,33]. Interestingly, we found that AGA caused greater dissatisfaction and psychological impairment among patients adopting coping strategies. Patients, who used invasive coping method for instance hair transplantation, were completely dissatisfied with their hair condition and experienced mild anxiety and severe depression than those who used non-invasive coping methods. Similar results were also reported by Cash et al. [10] and Zhuang et al. [28] who discovered patients who were actively seeking dermatologic treatment were substantially more distressed and anxious compared to nontreatment-seeking group. We postulate that those who adopted invasive coping mechanism were most psychologically affected and had the worst expectations of their condition. Kranz et al. [29] and Cartwright et al. [23] explained that problem-focused strategies for example active coping and instrumental support may not be effective in uncontrollable situations where little change can be done. Therefore, successful coping is best pursued via active emotional coping such as acceptance of changes in appearance [29] or improve psychological health to cope with the distress caused by AGA [27]. Psychological counselling and social support network can be utilized to restore the integrity of patient's personality functioning, self-assurance, minimize stigmatization and improve patient's outlook towards life [27,34]. Therefore, it is pivotal for the practitioners to address various psychological issues arising from AGA to improve the overall treatment outcome. Inappropriate use of cosmetic aids or camouflaging products might also contribute to less hair satisfaction $[22,35]$. For instance, hair styling and camouflaging are often not enough to conceal moderate to severe alopecia. Thus, an integration of hairpiece or wig may be better options for advanced stages of hair loss $[14,15,36,37]$. In such circumstances, the practitioner's role in guiding the patients to obtain the appropriate cosmetic aids or camouflages may also be able to lessen patients' anxiety and depression. 


\section{Conclusion}

AGA leads to anxiety and depression especially in women. Patient's perception on their disease severity determines the severity of the psychological impact. Young age less than 40 years old, single, females with shorter disease durations are the ones most adversely affected by the disease. Adopting coping methods without acceptance of the disease leads to adverse psychological impact. Therefore, early psychological support to facilitate acceptance of disease is recommended in AGA management.

\section{Acknowledgement}

We are indebted to all the staff in the dermatology clinics of The National University of Malaysia Medical Centre and Kuala Lumpur General Hospital for their help in conducting this study.

\section{References}

1. Yin YL, Chew CK (2012) A 10-year retrospective review of non-scarring alopecia in a tertiary hospital in Malaysia. Malay J Dermatol 29: 12-15.

2. Kapadia N, Ahmad TJ, Borhany T (2008) Male androgenetic alopecia treated with finasteride. J Pak Assoc Dermatol 18: 232-234.

3. Paik JH, Yoon JB, Sim WY, Kim BS, Kim NI (2001) The prevalence and types of androgenetic alopecia in Korean men and women. Br J Dermatol 145: 95-99.

4. Wang TL, Zhou C, Shen YW, Wang XY, Ding XL, et al. (2010) Prevalence of androgenetic alopecia in China: a community-based study in six cities. Br J Dermatol 162: 843-847.

5. Tang PH, Chia HP, Cheong LL, Koh D (2000) A community study of male androgenetic alopecia in Bishan, Singapore. Singapore Med J 41: 202-205.

6. Dermatological Society of Malaysia [WWW document]

7. Malaysian Society for Hair Science 2006. [WWW document].

8. Van der Donk J, Passchier J, Dutree-Meulenberg RO, Stolz E, Verhage F (1991) Psychologic characteristics of men with alopecia androgenetica and their modification. Int J Dermatol 30: 22-28.

9. Schmidt S, Fischer TW, Chren MM, Strauss BM, Elsner P (2001) Strategies of coping and quality of life in women with alopecia. Br J Dermatol 144: 1038-1043.

10. Cash TF, Price VH, Savin RC (1993) Psychological effects of androgenetic alopecia on women: comparisons with balding men and with female control subjects. J Am Acad Dermatol 29: 568-575.

11. Alfonso M, Richter-Appelt H, Tosti A, Viera MS, García M (2005) The psychological impact of hair loss among men: a multinational European study. Curr Med Res Opin 21: 1829-1836.

12. Eckert J (1976) Diffuse hair loss in women: the psychopathology of those who complain Acta Psychiatr Scand 53: 321-325.

13. Sinclair RD, Dawber RP (2001) Androgenetic alopecia in men and women. Clin Dermatol 19: 167-178.

14. Rogers NE, Avram MR (2008) Medical treatments for male and female pattern hair loss. J Am Acad Dermatol 59: 547-566.

15. Dinh QQ, Sinclair R (2007) Female pattern hair loss: current treatment concepts. Clin Interv Aging 2: 189-199.

16. Reid EE, Haley AC, Borovicka JH, Rademaker A, West DP, et al. (2010) Clinical severity does not reliably predict quality of life in women with alopecia areata, telogen effluvium, or androgenic alopecia. J Am Acad Dermatol 66: e97-102.

17. Luo N, Wang Y, How CH, Tay EG, Thumboo J, et al. (2015) Interpretation and use of the 5-level EQ-5D response labels varied with survey language among Asians in Singapore. J Clin Epidemiol 68: 1195-1204.

18. Aghaei S, Saki N, Daneshmand E, Kardeh B (2014) Prevalence of psychological disorders in patients with alopecia areata in comparison with normal subjects. ISRN Dermatol 2014: 304370.

19. Seçil Aldemir SE, Ercan D, Seda T, Merve T, Seval E (2015) Anger, anxiety and depression in females with diffuse alopecia. Dicle Med J 42: 335-341.

20. Yu NL, Tan H, Song ZQ, Yang XC (2016) Illness perception in patients with androgenetic alopecia and alopecia areata in China. J Psychosom $86: 1-6$.

21. Tabolli S, Sampogna F, di Pietro C, Ribuffo M, Abeni D, et al. (2013) Health status, coping strategies, and alexithymia in subjects with androgenetic alopecia: a questionnaire study. Am J Clin Dermatol 14: $139-145$

22. Han SH, Byun JW, Lee WS, Kang H, Kye YC, et al. (2012) Quality of life assessment in male patients with androgenetic alopecia: result of a prospective, multicenter study. Ann Dermatol 24: 311-318.

23. Cartwright T, Endean N, Porter A (2009) Illness perceptions, coping and quality of life in patients with alopecia. Br J Dermatol 160: 1034-1039.

24. Wells PA, Willmoth T, Russell RJ (1995) Does fortune favour the bald? Psychological correlates of hair loss in males. Br J Psychol 86: 337-344.

25. Price VH (2003) Androgenetic alopecia in adolescents. Cutis 71: 115-121.

26. Girman CJ, Rhodes T, Lilly FR, Guo SS, Siervogel RM, et al. (1998) Effects of self-perceived hair loss in a community sample of men. Dermatology 197: 223-229.

27. Sawant N, Chikhalkar S, Mehta V, Ravi M, Madke B, et al. (2010) Androgenetic Alopecia: Quality-of-life and Associated Lifestyle Patterns. Int J Trichol 2: 81-85.

28. Zhuang XS, Zheng YY, Xu JJ, Fan WX (2013) Quality of life in women with female pattern hair loss and the impact of topical minoxidil treatment on quality of life in these patients. Exp Ther Med 6: 542-546.

29. Kranz D (2011) Young men's coping with androgenetic alopecia: acceptance counts when hair gets thinner. Body Image 8: 343-348.

30. Tahir K, Aman S, Nadeem M, Kazmi AH (2013) Quality of Life in Patients with Androgenetic Alopecia. Annals 19: 150-154.

31. Cash TF (1992) The psychological effects of androgenetic alopecia in men. J Am Acad Dermatol 26: 926-931.

32. Lee WS, Lee HJ (2012) Characteristics of androgenetic alopecia in asian. Ann Dermatol 24: 243-252.

33. Ramazanpour A, Gochai J, Ghanbari A, Alizadeh N, Darjani A, et al. (2012) A comparative study on health-related quality of life in healthy people and patients with alopecia areata. World Appl Sci J 18: 689-692.

34. Picardi A, Pasquini P, Cattaruzza MS, Gaetano P, Baliva G, et al. (2003) Psychosomatic factors in first-onset alopecia areata. Psychosomatics 44: 374-381.

35. Kim HJ, Sim WY, Song JY (2001) Assessment of the Characteristics of Illness Behavior and Quality of Life in Patients with Androgenetic Alopecia. Korean J Dermatol 39: 1094-1099.

36. Inui S, Inoue T, Itami S (2013) Psychosocial impact of wigs or hairpieces on perceived quality of life level in female patients with alopecia areata. J Dermatol 40: 225-226.

37. Inui S, Inoue T, Itami S (2013) Effect of wigs on perceived quality of life level in androgenetic alopecia patients. J Dermatol 40: 223-225. 